\section{Current Treatment Approaches for PTSD-Substance Use Disorder Comorbidity}

\author{
Bryce Hruska $^{1}$ and Douglas L. Delahanty ${ }^{1,2 *}$
}

Recent years have seen a rise in the number of empirically supported treatments for Post Traumatic Stress Disorder (PTSD) [1]. One of the most effective treatments is prolonged exposure (PE), which involves in vivo and imaginal exposure to avoided cues and reminders related to a trauma in order to aid in emotionally processing memories of that traumatic event [2]. However, despite the effectiveness of treatments including PE, efforts to treat PTSD are often complicated by the presence of comorbidities; perhaps most commonly, comorbid substance use disorder (SUD) which affects nearly $50 \%$ of people with PTSD [3]. This prevalence is notable given that people with PTSD-SUD experience greater physical and psychosocial impairments compared to people with either disorder alone [4,5]. Given the prevalence and cost associated with PTSDSUD, recent years have seen research attention turn to approaches that can effectively address this comorbidity. These approaches can best be described as either sequential (one disorder addressed prior to the other) or integrated (both disorders addressed concurrently).

Based largely on concerns that substance use would interfere with PTSD treatment; historically, interventions for people with PTSDSUD have focused first on SUD symptoms and then on PTSD in a sequential manner. However, patients with comorbid PTSD-SUD have poorer short- and long-term SUD treatment outcomes than patients with SUD alone [6,7] and delaying treatment for PTSD has been found to result in greater SUD relapse rates in people with PTSD-SUD despite their greater use of costly addiction treatment services [8,9]. Collectively, findings such as these have led researchers to hypothesize that failure to address underlying psychopathology may hinder initial SUD therapy attempts.

More recent research has examined integrated interventions in which PTSD and SUD symptoms are addressed concurrently [10]. The potential benefits of concurrent treatment have been noted [11], and these interventions have shown promise. However, concurrent treatments have only been tested in small pilot studies [12], have produced relatively small improvements in symptoms [13], or have resulted in high drop-out rates [14]. Further, combining two interventions may overwhelm participants to an extent, resulting in less effective treatment than a single treatment [15], and implementing concurrent treatments for people with PTSD-SUD

${ }^{*}$ Corresponding author: Douglas L. Delahanty, Department of Psychology, 118 Kent Hall, Kent State University, Kent, OH 44242, USA, Tel: (330) 672-2395; Fax: (330) 672-3786; E-mail: ddelahan@kent.edu

Received: September 17, 2012 Accepted: September 22, 2012 Published: September 29, 2012 is cited by clinicians as one of the most challenging approaches for treating this comorbidity [16].

One approach that has not been previously examined is to test the potential efficacy of sequential treatments in which PTSD symptoms are addressed prior to SUD. Despite aforementioned concerns, more recent research has demonstrated the efficacy of exposure therapies in reducing PTSD severity in PTSD-SUD patients $[17,18]$. Addressing psychiatric symptoms prior to addressing SUD may remove barriers to successful SUD implementation and increase the success of SUD treatment. In line with tension-reduction hypotheses, addressing PTSD first may remove the source of tension that is driving substance use. Despite the merits of a sequential approach that initially targets PTSD as well as the potential efficacy of incorporating PE as part of that treatment, virtually no research has attempted to test such a treatment. Given the limitations associated with each of the treatment approaches described above, and the public health impact of comorbid PTSD-SUD, research should explore the efficacy of sequential PTSD then SUD treatment for people with PTSD-SUD.

\section{References}

1. Bradley R, Greene J, Russ E, Dutra L, Westen D (2005) A multidimensional meta-analysis of psychotherapy for PTSD. Am J Psychiatry 162: 214-227.

2. Foa EB (2000) Psychosocial treatment of posttraumatic stress disorder. J Clin Psychiatry 61: 43-48.

3. Pietrzak RH, Goldstein RB, Southwick SM, Grant BF (2011) Prevalence and axis I comorbidity of full and partial posttraumatic stress disorder in the United States: Results from wave 2 of the National Epidemiologic Survey on Alcohol and Related Conditions. J Anxiety Disord 25: 456-465.

4. Ouimette P, Goodwin E, Brown PJ (2006) Health and well being of substance use disorder patients with and without posttraumatic stress disorder. Addict Behav 31: 1415-1423.

5. Riggs DS, Rukstalis M, Volpicelli JR, Kalmanson D, Foa EB (2003) Demographic and social adjustment characteristics of patients with comorbid posttraumatic stress disorder and alcohol dependence: Potential pitfalls to PTSD treatment. Addict Behav 28: 1717-1730.

6. Reynolds M, Mezey G, Chapman M, Wheeler M, Drummond C, et al. (2005) Co-morbid post-traumatic stress disorder in a substance misusing clinical population. Drug Alcohol Depend 77: 251-258.

7. Stewart SH, Conrad PJ (2003) Psychosocial models of functional associations between post traumatic stress disorder and substance use disorder. P. Ouimette \& P.J. Brown Trauma and Substance Abuse: Causes, Consequences, and Treatment of Co-Morbid Disorders (1st ed.), pp. 29-55. Washington, DC: American Psychological Association.

8. Brown PJ, Stout RL, Mueller T (1999) Substance use disorder and posttraumatic stress disorder comorbidity: Addiction and psychiatric treatment rates. Psychology of Addictive Behaviors 13: 115-122.

9. Ouimette PC, Ahrens C, Moos RH, Finney JW (1997) Posttraumatic stress disorder in substance abuse patients: Relationship to 1-year posttreatment outcomes. Psychology of Addictive Behaviors 11: 34-47.

10. Riggs DS, Foa EB (2008) Treatment for co-morbid posttraumatic stress disorder and substance use disorders. S.H. Stewart \& P.J. Conrod (Eds.), Anxiety and Substance Use Disorders, (pp. 119-137). New York, NY: Springer Press.

11. Ouimette P, Moos RH, Brown PJ (2003) Substance use disorder-posttraumatic stress disorder co-morrbidity: A survey of treatments and proposed practice guidelines. P.J. Ouimette \& P.J. Brown (Eds.), Trauma and Substance 
Abuse: Causes, Consequences, and Treatments of Co-Morbid Disorders ( $1^{\text {s }}$ ed.), pp. 91-111. Washington DC: American Psychological Association.

12. Triffleman E (2000) Gender differences in a controlled pilot study of psychosocial treatments in substance dependent patients with post-traumatic stress disorder: Design considerations and outcomes. Alcoholism Treatment Quarterly 18: 113-126.

13. Donovan B, Padin-Rivera E, Kowaliw S (2001) "Transcend": Initial outcomes from a posttraumatic stress disorder/substance abuse treatment program. J Trauma Stress 14: 757-772.

14. Brady KT, Dansky BS, Back SE, Foa EB, Carroll KM (2001) Exposure therapy in the treatment of PTSD among cocaine-dependent individuals: Preliminary findings. J Subst Abuse Treat 21: 47-54
15. Foa EB, Rothbaum BO (1998) Treating the Trauma of Rape. New York: The Guilford Press.

16. Back SE, Waldrop AE, Brady KT (2009) Treatment challenges associated with comorbid substance use and posttraumatic stress disorder: Clinicians' perspectives. Am J Addict 18: 15-20.

17. Berenz EC, Rowe L, Schumacher JA, Stasiewicz PR, Coffey SF (2012) Prolonged exposure therapy for posttraumatic stress disorder among individuals in a residential substance use treatment program: A case series. Professional Psychology: Research and Practice 43: 154-161.

18. Souza TM, Spates RC, Rankin C (2012) Prolonged exposure to posttraumatic stress disorder (PTSD) in an active substance abuser. Mental Health and Substance Use 5: 102-114.

\section{Author Affiliations}

${ }^{1}$ Kent State University, Department of Psychology, Ohio, USA

${ }^{2}$ Northeastern Ohio Medical University (NEOMED), Department of Psychology in Psychiatry, Rootstown, Ohio, USA

Submit your next manuscript and get advantages of SciTechnol submissions

* 50 Journals

* 21 Day rapid review process

- 1000 Editorial team

- 2 Million readers

- More than 5000 facebogk

- Publication immediately after acceptance

- Quality and quick editorial, review processing

Submit your next manuscript at $\bullet$ www.scitechnol.com/submission 